\title{
Stage A 前立腺癌の臨床検討
}

一特に Stage A1と Stage A2の分類についてー

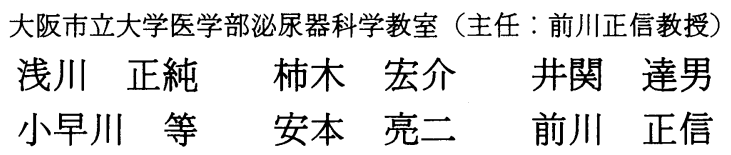

\section{CLINICAL STUDY OF STAGE A PROSTATIC CANCER:}

With Special Reference to the Classification between Stage $A_{1}$ and $A_{2}$ Diseases

\author{
Masazumi Asakawa, Khosuke Kakinoki, Tatuo Iseki, Hitoshi Kobayakawa, \\ Ryoji Yasumoto and Masanobu Maekawa \\ Department of Urology, Osaka City University Medical School
}

(Director: Prof. M. Maekawa)

Between January in 1977 and December in 1987, 1384 surgical interventions including transurethral resection (TUR) and open subcapsular removal of the prostate were done in the treatment of benign prostatic hypertrophy (BPH) at the University Hospital and the affiliate teaching hospitals. Postoperatively, 33 patients were incientally found to have cancerous foci on the histopathologic examinations of the surgically removed specimen from the patients with BPH. In the present study, patient chart was reviewed to assess the treatment modalities and prognosis in 33 patients with stage A prostatic cancer. In order to circumvent the pirfally of expensive and time spending hitopaghological examination for conventioanl subclassification of stage A prostatic cancer, the simplest clinical staging was employed to classify stage $A_{1}$ and $A_{2}$ diseases of incidentally found, namely occult cancer of the prostate. According to our proposed classification, a well and moderately or poorly differentiated prostatic adenocarcinoma of stage $A$ noudules were respectively referred to $A_{1}$ and $\mathrm{A}_{2}$. The analysis of the clinical observations is summerized as follow.

1) The thirty-three patients comprised 24 in stage $A_{1}$ and 9 in stage $A_{2}$ diseases.

2) Incidental cancer in the surgical specimen was found in 21 patients (1.9 percent) by TUR of 1120 operations and in 12 patients ( 4.5 percent) by subcapsular prostatectomy in 264 open procedures.

3 ) Of the 33 patients with stage A cancer, 28 was additionally managed by appropriate therapy and the remaining 5 received no further treatment.

4) A relapse was observed in 4 patients with stage $A_{2}$ cancer although none of the patients with stage $A_{1}$ disease relapsed.

5) All 3 patietns with stage A prostatic cancer survived through the follow-up period.

These clinical findings suggest that our subclassification of stage A prostatic cancer is easily applicable and replaces the conventional staging of stage A disease to select the patients for suitable further management in a clinical setting.

\footnotetext{
要旨：1977年 1 月から1987年12月末すでの11年間に大阪市大及びその関連施設で前立腺肥大症として transurethral resection of the prostatic gland (TUR-P), あるいは open surgery of the prostatic gland (Open surgery) を施行された1,384例のらち, 術後 Stage A 前立腺癌と診断された33症例に対し て治療法, 予後等の臨床的検討を行った。 また, Stage A 前立腺癌の subclass 分類では, 癌の病理組織 学的分化度が高分化型の場合を $\mathrm{A} 1$ ，それ以外を A2 と分類した。

（1）33症例の subclass 分類では, Stage A1 24例, Stage A2 9 例であった.

(2) Stage A 前立腺癌の頻度は, TUR-P 後で21例 (1.9\%), Open surgery 後で12例 (4.5\%) であっ
} 
た.

（3） Stage A 前立腺癌33症例のらち，28例には何らかの治療が行なわれ，5例は無治療であった.

(4) Stage A2における Progressionは4 例であったが, Stage A1では Progressionはみられなかっ た.

（5） Stage A1，A2の 5 年生存率はともに $100 \%$ で有意差はみられなかった.

\section{緒言}

前立腺肥大症に対する手術機会が増えるにつれて Stage A 前立腺癌も増加の傾向にある。一般に Stage $\mathrm{A}$ 前立腺癌の臨床経過は良好と言われているが，まれ に進行癌へ進む例もあり, Stage A をさらにA1と A2 に分類することが提唱された ${ }^{1)}$. A1, A2の subclass 分 類は, 癌の病理組織学的分化度とその病巣の大きさと いう2つの要素で行なわれるべきであるという点では 従来から一致していたが, 現時点では, 癌病巣の大き さに対する具体的な基準が統一されていない，今回， 我々はStage A 前立腺癌33例の臨床経過を検討する とともに stage A の subclass 分類について考察を加 えた。

\section{対象と方法}

対象症例は，1977年 1 月から1987年12月末すでの11 年間に大阪市大泌尿器科及びその関連施設で診断され た Stage A 前立腺癌33例である. 前立腺癌が発見され た手術は, 21例が TUR-P(63.6\%), 12例が Open surgery (36.4\%)であった. 33例の年齢は59歳から85歳, 平均72.3歳であった. $\mathrm{A} 1, \mathrm{~A} 2$ の分類基準としては, 前 立腺癌取り扱い規約に従った病理組織学的分化度のみ を基準とし高分化型を $\mathrm{A} 1$ ，それ以外を $\mathrm{A} 2$ とした。

\section{結 果}

Stage A 前立腺癌の発現頻度は, TUR-P 後では 1,120 例中 21 例 (1.9\%), Open surgery 後では264例中 12例 (4.5\%) であった。 また Stage A1は24例, Stage A2は 9 例であった（Table 1).

Table 1 Stage A 前立腺癌の一覧

\begin{tabular}{cc|c}
\hline 症例数 & 33 & 発見された手術 \\
$\mathrm{A}_{1}$ & 24 & TUR-P 21 $(63.6 \%)$ \\
$\mathrm{A}_{2}$ & 9 & Open $12(36.4 \%)$ \\
年齢分布 & & \multicolumn{2}{|c}{ 発現頻度 } \\
$50 \sim 59$ & 1 & \multicolumn{2}{|c}{ TUR-P 1.9\% } \\
$60 \sim 69$ & 8 & Open $4.5 \%$ \\
$70 \sim 79$ & 21 & \\
$80 \sim 89$ & 3 & Progression \\
平均年齢 & 72.3 & $\mathrm{~A}_{1} \quad 0$ \\
& & $\mathrm{~A}_{2} \quad 4$ \\
\hline
\end{tabular}

治療については，何らかの治療を行なっているもの が28例（84.8\%)，無治療 5 例（15.2\%）であった。治 療内容としては, 去勢術のみが 3 例, 去勢術十ホルモ ン療法が 6 例, 去勢術十ホルモン療法十化学療法が 5 例, ホルモン療法のみが 8 例, ホルモン療法十化学療 法が 3 例, 去勢術十化学療法が 3 例であった. Stage $\mathrm{A} 1$ の追跡期間は平均 44.4 力月（2 力月～128力月）, Stage A2の追跡期間は平均 25.5 力（10力月～54力 月）であった (Table 2). 追跡中に Progression が明 らかになったのは Stage A2の 4 例だけであった (Fig. 1)。また，去勢術の有無による Progression の比較で は両群に有意な差はみられなかった (Fig. 2). 初診か ら Progression までの期間は, 12 力から 36 月正平

Fig. 1 病期に括ける比較 (A1/A2)

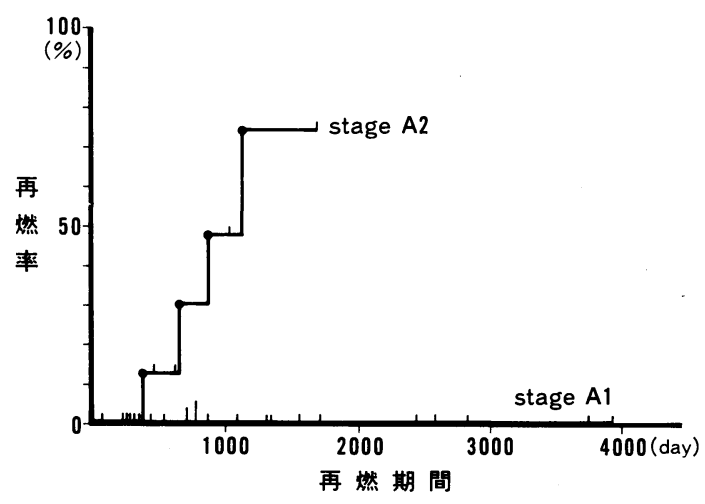

Fig. 2 去勢術における比較（有/無）

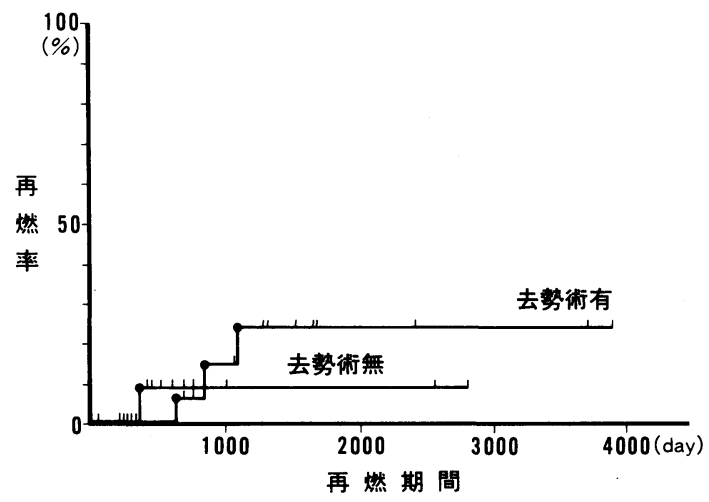


Table 2 Stage A 前立腺癌の概要

\begin{tabular}{|c|c|c|c|c|c|c|c|c|c|}
\hline \multicolumn{3}{|c|}{ 症 例 } & \multirow{2}{*}{$\frac{\text { 年 齢 }}{75}$} & \multirow{2}{*}{$\frac{\text { 分化度 }}{\text { 高 }}$} & \multirow{2}{*}{$\begin{array}{c}\text { 病 期 } \\
A_{1} \\
\end{array}$} & \multirow{2}{*}{$\begin{array}{l}\text { 治 療 } \\
\text { 去, 木 }\end{array}$} & \multirow{2}{*}{ 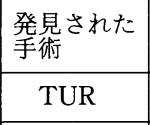 } & \multirow{2}{*}{$\begin{array}{l}\text { 再然までの } \\
\text { 期間 (月) }\end{array}$} & \multirow{2}{*}{$\begin{array}{c}\frac{\begin{array}{c}\text { 追跡期間 } \\
(\text { ) }\end{array}}{35} \\
35\end{array}$} \\
\hline 1. & 中 & & & & & & & & \\
\hline 2. & 永 & 0 & 72 & 中 & $\mathrm{A}_{2}$ & 去, 木 & TUR & 28 & 29 \\
\hline 3. & 滰 & 0 & 65 & 高 & $\mathrm{A}_{1}$ & 去, 木 & TUR & & 28 \\
\hline 4. & 原 & 0 & 73 & 高 & $\mathrm{A}_{1}$ & 去, 木 & TUR & & 24 \\
\hline 5. & 落 & 0 & 77 & 高 & $\mathrm{A}_{1}$ & 去, 木 & TUR & & 23 \\
\hline 6. & 浜 & 0 & 64 & 高 & $\mathrm{A}_{1}$ & 去, 木, 化 & TUR & & 11 \\
\hline 7. & 矢 & 0 & 72 & 高 & $\mathrm{A}_{1}$ & 去 & OPEN & & 11 \\
\hline 8. & 木 & 0 & 78 & 中 & $\mathrm{A}_{2}$ & 去, 木, 化 & TUR & & 10 \\
\hline 9. & 姫 & 0 & 66 & 高 & $\mathrm{A}_{1}$ & 去, 木 & OPEN & & 128 \\
\hline 10. & 河 & 0 & 73 & 高 & $\mathrm{A}_{1}$ & 去, 化 & OPEN & & 55 \\
\hline 11. & 小 & 0 & 76 & 高 & $\mathrm{A}_{1}$ & 木, 化 & TUR & & 89 \\
\hline 12. & 中 & 0 & 78 & 高 & $A_{1}$ & 木, 化 & TUR & & 14 \\
\hline 13. & 島 & 0 & 76 & 高 & $\mathrm{A}_{1}$ & なし & TUR & & 23 \\
\hline 14. & 道 & 0 & 70 & 中 & $\mathrm{A}_{2}$ & 木 & OPEN & 12 & 34 \\
\hline 15. & 大 & 0 & 75 & 中 & $\mathrm{A}_{2}$ & 木 & OPEN & & 33 \\
\hline 16. & 小 & 0 & 66 & 低 & $\mathrm{A}_{2}$ & 去 & OPEN & & 54 \\
\hline 17. & 山 & 0 & 73 & 中 & $\mathrm{A}_{2}$ & なし & OPEN & & 15 \\
\hline 18. & 応 & 0 & 60 & 中 & $\mathrm{A}_{2}$ & なし & OPEN & & 20 \\
\hline 19. & 林 & 0 & 77 & 高 & $\mathrm{A}_{1}$ & 去 & OPEN & & 121 \\
\hline 20. & 北 & 0 & 63 & 中 & $\mathrm{A}_{2}$ & 去, 木, 化 & OPEN & 36 & 125 \\
\hline 21. & 野 & 0 & 78 & 高 & $\mathrm{A}_{1}$ & なし & OPEN & & 72 \\
\hline 22. & 山 & 0 & 85 & 高 & $\mathrm{A}_{1}$ & なし & TUR & & 91 \\
\hline 23. & 藤 & 0 & 75 & 高 & $\mathrm{A}_{1}$ & 木 & TUR & & 7 \\
\hline 24. & 山 & 0 & 80 & 高 & $\mathrm{A}_{1}$ & 木 & TUR & & 9 \\
\hline 25. & 上 & 0 & 64 & 高 & $A_{1}$ & 木 & TUR & & 24 \\
\hline 26. & 深 & 0 & 78 & 高 & $\mathrm{A}_{1}$ & 木 & TUR & & 24 \\
\hline 27. & 芦 & 0 & 84 & 高 & $\mathrm{A}_{1}$ & 木 & TUR & & 8 \\
\hline 28. & 大 & 0 & 72 & 高 & $A_{1}$ & 木, 去 & TUR & & 49 \\
\hline 29. & 近 & 0 & 62 & 高 & $\mathrm{A}_{1}$ & 木 & TUR & & 2 \\
\hline 30. & 森 & 0 & 75 & 高 & $\mathrm{A}_{1}$ & 去, 化 & OPEN & & 79 \\
\hline 31. & 白 & 0 & 72 & 高 & $\mathrm{A}_{1}$ & 去, 化 & TUR & & 43 \\
\hline 32. & 青 & 0 & 59 & 高 & $\mathrm{A}_{1}$ & 去, 木, 化 & TUR & & 42 \\
\hline 33. & 今 & 0 & 71 & 中 & $\mathrm{A}_{2}$ & 去, 木, 化 & TUR & 21 & 21 \\
\hline
\end{tabular}

去:去勢術

ホ：ホルモン療法

化 : 化学潦法 
均24.3カ月であった. Progression の様式は全例骨転 移であった。1987年12月の時点では33例すべての生存 が確認できているため, Stage A1, A2の 5 年生存率は ともに100\%であった。

\section{考 察}

Stage A 前立腺癌（A 癌）の発現頻度は前立腺肥大 症に対する手術の $5 \%$ ２0\%と言われているが2) 66), 今後前立腺肥大症の手術機会が増えるにつれて $\mathrm{A}$ 癌 も増加することが予想される，A 癌は無治療のままで も進行せず予後良好な例が多いが，癌が影性化し癌死 する例もあることが報告されて以来 ${ }^{788)}, \mathrm{A}$ 癌を分化度 と病巣の大きさの 2 つの要素から $\mathrm{A} 1$ と $\mathrm{A} 2$ に細分化 する方法が提唱されてきた ${ }^{11}$. 現在でもその統一され た基準はみられないがその理由として，病巣の大きさ といら要素に対する基準が一定していないことが考兄 られる。滝川ら ${ }^{9}$ は, 標本の $10 \%$ 以下癌がみられる場 合を Focal，それ以外をDiffuse と分類し，分化度との 組み合わせで $\mathrm{A} 1 ， \mathrm{~A} 2$ の subclass 分類を報告し， A1と A2の予後に差が見られたことから, subclass 分類にあ たっては分化度と病巣の大きさを考慮することが大切 だと言っている。内田ら ${ }^{10)}$ は，高分化型（あるいは Gleason score 2 4) でかつ腫瘍組織切片が総検索切 片の $5 \%$ 以下の場合を $\mathrm{A} 1, \mathrm{~A} 1$ 以外を $\mathrm{A} 2$ と定義してい る。これらはいずれも，従来からあいまいであった病 巣の大きさという要素に具体的な基準を決めているた め非常に理解しやすい分類である。 また Sheldon ら ${ }^{11)}$ が言らように分化度と病巣の大きさは切り離して考兄 られないという点からみても，2つの要素を組み合わ せたこれらの分類は合理的な分類であろう。しかしな がら現実的には, TUR-P後の切除切片すべての病理 標本を作製することは極めて困難であり，また各施設 間でその標本切片数に大きな差がある場合，前述のよ らな病巣の大きさに対する基準では癌の広がりを充分 反映し得ないのではないだろらか。 むしろ全切除切片 の病理組織学的検索を行ない, 腫瘍組織のみられた切 片数の全体に対する割合に基準を設定するか，あるい は全切片数の何\%以上を検索すべきかを決めて，さら に検索切片の何\%に腫瘍組織切片がみられたかを設定 し，病巣の大きさを推定すべきであろう。もしこのよ らな基準を定めても，それに従い分類できない場合は， 我々が行なった分化度だけで subclass 分類せざるを 得ないであろう. 今回, 我々が行なった分類の A1, A2 の全症例が現時点で生存しているため， 5 年生存率は ともに $100 \%$ で有意差はみられないが，A1における
Progressionはなく, Progression がみられた 4 例はす べて A2であったことから考えると，分化度のみによ る分類でも A1，A2の予後をある程度判定し得るもの と思われた（Fig. 1).

次に A1，A2に対する治療法については，A1は無治 療のまま経過観察すると言う報告144)12113)が多く, A2に ついては，ホルモン療法，化学療法等何らかの治療の 必要があるとする報告4)14)15)がみられる。さらには，A2 には前立腺全摘出術を行ならべきであるとの報告もあ $\eta^{16) 17)}$ ，また， A 癌全体としてホルモン療法が必要であ るとする報告すみられる ${ }^{18)}$.

今回の検討では，33例中 28 例 (84.8\%) に何らかの 治療を施行しているが, Fig. 2 に示すよ5に治療法に よる予後の差はみられなかった。

今回の検討では，A1 24例，A2 9 例と症例数も少な $<$, 観察期間名 A1 44.4力月（2 力月～128力月， A2 25.5 力月（10カ月～54 月月）と短かいが，長期 follow up 中に A1でも $16 \%$ に progression がみられたとする 報告19) もあり,今後も原則として A1にはホルモン療法 (可能な場合は去勢術の施行), A2にはホルモン療法と 化学療法の併用療法を施行し，経過を追跡していく予 定である。

\section{結 語}

Stage A 前立腺癌の治療法, 予後等の臨床的検討を 行ならとともに， subclass 分類について検討した.

（1）1977年 1 月から1987年12月末までの11年間に, 大阪市立大学泌尿器科で経験した Stage A 前立腺癌 は33例で，その発現率は2.4\%であった。

（2）高分化型を Stage A1，それ以外を Stage A2 と 分類した。

（3） Stage A1 24例，Stage A2 9 例の 5 年生存率は ともに $100 \%$ で有意差はみられなかった。

(4) Stage A1では Progressionはみられなかった が, Stage A2では 4 例に Progression が生じた。

以上の結果より, 前立腺癌の Progression を予測す るには，分化度だけですある程度可能であると考兄ら れた。

本論文の要旨は，第76回日本泌尿器科学会総会にて発表 した.

\section{文 献}

1) Jewett, H.J.: The present status of radical prostatectomy for stage $\mathrm{A}$ and $\mathrm{B}$ prostatic cancer. Urol. Clin. N. Amer., 2, 105-124, 1975.

2) Denton, S.E., CHoy, S.H. and Valk, W.L.: 
Occult prostatic carcinoma diagnosed by the step-section technique of the surgical specimen. J. Urol., 93, 296-298, 1965.

3) Delides, G.S., Baltopoulos, G. and Papharalampous, N.X. : Latent carcinoma of theprostate: The probility of identifying small lesions in routine histology. Brit. J. Urol., 48, 207-209, 1979.

4）横山正夫, 河村 毅, 福谷恵子, 東海林病夫, 鈴木 徹, 金村三樹郎：手術標本の病理学的検索で発見 された前立腺癌の治療法とその成績. 日泌尿会誌, 73, 1269-1276, 1982.

5）黒田昌男, 古武敏彦, 宇佐美道之, 清原久和, 三木 恒治, 吉田光良, 細木 茂, 石里信悟：前立腺肥大 症における連続平行割面による潜在癌の検索。日 泌尿会誌，74，401-408，1983.

6) 大西哲郎, 飯塚典男, 田所 衛, 品川俊人, 小寺重 行, 増田富士男, 町田豊平: 経尿道的前立腺切除術 で発見される偶発前立腺癌. 日泌尿会誌, 77, 963-968, 1986.

7) Bauer, W.C., Mcgavran, M.H. and Carlic, M.R. : Unsuspected carcinoma of the prostate in suprapubic prostatectiomy specimens: A clinicopathological study of 55 consecutive cases. Cancer, 13, 370-378, 1960.

8) Lehman, T.H., Kirchheim, D., Braun, E. and Moore, R.: An evaluation of radical proscinoma of the prostate. J. Urol., 99, 646-650, 1968.

9）滝川 浩, 香川 征, 黒川一男 : 前立腺癌 Stage A の臨床的検討。日泌尿会誌, 78, 470-476, 1987.

10）内田豊昭, 本田直康, 青 輝昭, 小紫 健, 桑尾定 化：経尿道的前立腺切除術後に発見された偶発性 前立腺癌の病理組織学的検討一Stage A1 Stage A2 分類の試み一, 日泌尿会誌, 78, 2122 -2132, 1987.
11) Sheldon, C.A., Williams, R.D. and Fraley, E.E. : Incidental carcinoma of the prostate: A review of the literature and clinical reappraisal of classification. J. Urol., 124, 626-631, 1980.

12) Cantrell, B.B., Deklerk, D.P., Eggleston, J.C., Boitnott, J.K. and Walsh, P.C.: Pathological factors that influence prognosis in stage $\mathrm{A}$ prostatic cancer: The influence of extent versus grade. J. Urol., 125, 516-520, 1981.

13) Bartsch, G., Dietze, O., Hohlbrugger, H. and Mikuz, G. : Incidental carcinoma of th prostate-Grading and tumor volume in r elation to survival rate. World. J. Urol., 1, 24-28, 1983.

14) Barnes, R., Hirst, A. and Rosequist, R. : Early carcinoma of prostate: Comparison of stage A and B. J. Urol., 115, 404-405, 1976.

15) Golimbu, M., Schinella, R., Morales, P. and Kurusu, S.: Differences in pathological characteristics and prognosis of clinical A2 prostatic cancer from $\mathrm{A} 1$ and $\mathrm{B}$ disease. J. Urol., 119, 618-622, 1978.

16) Elder, J.S., Gibbions, R.P., Correa, R.J. and Brannen, G.E.: Efficacy of radical prostatectiomy for stage A2 carcinoma of the prostate Cancer, 56, 2151-2154, 1985.

17) Fowlor, J.E.: Radical prostatectomy for stage A2 and B prostatic carcinoma. Urology, 26, $1-3,1985$.

18）浅川正純, 安本亮二, 上水流雅人, 前川正信：経尿 道的前立腺切除術で見つかった偶発前立腺癌. 泌 尿紀要，34，1003-1005，1988.

19) Epstein, J.I., Paull, G., Eggleston, J.C. and Walsh, P.C. : Prognosis of untreated stage A1 prostatic carcinoma: A study of 94 cases with extended followup. J. Urol., 136, 837-839, 1986. （1988年 7 月 12 日受理，特別掲載） 